\title{
Do adolescents perceive the exposure to peer aggression at school as bullying victimization?
}

\section{$\underline{\text { Introduction }}$}

Traditional bullying is defined by Olweus as a type of aggressive behaviour by one or more individuals (perpetrators) with intent to cause harm to another individual (victim), having particular characteristics. These characteristics involve three basic criteria: (1) intentionality, where the perpetrator intended to injure or harm the target person, who is distressed by the exposure situation; (2) frequency, where aggressive behaviour occurs repeatedly; and (3) imbalance of power between aggressor and victim, and may be due to differences in physical strength, age, selfconfidence, popularity, group status, among others, making the victim feel insecure and perceive the situation as an intimidation [1]. Exposure to peer aggression at school is not always interpreted by adolescents as bullying victimization.

\section{Objectives}

Our study aims to estimate the prevalence of exposure to peer aggression events (having suffered physical aggression, verbal harassment and / or social manipulation); to estimate the prevalence of bullying victimization based on the self-perception of adolescents; and to verify the extent to which exposure to peer aggression at school is perceived as bullying by adolescents.

\section{$\underline{\text { Methods }}$}

This is a cross-sectional study nested in a longitudinal study entitled "Itaboraí Youth Study" that was conducted in Itaboraí, a low-income city from southeast Brazil (218,008 inhabitants, 98\% urban) by the Universidade Federal de São Paulo (Brazil) in collaboration with the University of Tromsø (Norway). The Itaboraí Youth Study investigated a population-based sample of 1,409 6-to-15-year olds at baseline (response rate $=87.8 \%$ ). A 3-stage probabilistic sampling procedure (random selection of census units, eligible households and target child) was used to generate sampling weights. At baseline, trained lay interviewers applied a semistructured questionnaire to mothers of all children ( $\mathrm{n}=689,6-10$ years) and to 680 (94.4\% of 720) adolescents (11-15-years). More detailed information on the Itaboraí Youth Study methods can be found elsewhere [2].

This poster analyses baseline data reported by in-school adolescents ( $\mathrm{n}=669)$. Measures of types of school violence investigated are described below.

\section{Exposure to violence at school (peer aggression events)}

A 15-item scale previously used in a Norwegian study with schoolchildren [3] investigated three types of peer aggression events: physical aggression (4 items), verbal harassment (5 items) and social manipulation (6 items). Possible answers for all items: "not at all" (0), "once" (1), "more than once" (2). Any peer aggression corresponded to at least one event occurring more than once in the past six months.

\section{Self-reported bullying victimization}

After investigating peer aggression events, the interviewer informed the adolescent about the definition of bullying ("when one or more school peers are repeatedly doing bad things to you such as name-calling, threatening, hitting, spreading rumours about you, excluding you from the group or teasing you to hurt your feelings"). Then, asked one question about self-perceived bullying victimization: "How often have you been bullied in the past six months?" Answers were coded as (0) "not at all", (1) "less than once a week", (2) "more than once a week" or (3) "most days". The frequency of more than once a week/most days identified repeated exposure.

\section{$\underline{\text { Results }}$}

The prevalence of exposure to one or more peer aggression events at school occurred more than once in the last six months was $21.9 \%(17.7 \%-26.6 \%)$. A total of 5.5\% (3.7\% $8.0 \%$ ) of in-school adolescents considered themselves to have been victims of bullying more than once a week in the last six months. Among adolescents who reported exposure to peer aggression at school, only $20.0 \%(13.1-29.4 \%)$ considered themselves victims of bullying.

Association between exposure to peer aggression events and bullying victimization

It was found a strong association between exposure to peer aggression events and self-perceived bullying victimization. It can be said that adolescents who considered themselves to be victims of bullying were 12 times more likely to have suffered peer aggression than those who did not consider themselves victims of bullying. Likewise, adolescents exposed to peer aggression events were 12 times more likely to consider themselves bully victims when compared to those who were not exposed.

\section{Conclusions}

The fact that perception of bullying requires adolescents to feel hurt or harmed by the peer aggression events explains why the prevalence of exposure to peer aggression events is higher than the prevalence of self-perceived bullying victimization (21.9\% vs. 5.5\%), and only $20.0 \%$ of adolescents suffering peer aggression considered themselves victims of bullying.

We consider important that prevalence studies on bullying present a previous definition of this phenomenon to the study participants that take into account the emotional impact of bullying on victims before asking questions on victimization.

\section{References}

1. Olweus D (2013) School bullying: Development and some important challenges. Annual Review of Clinical Psychology 9,751-780. doi: 10.1146/annurev-clinpsy050212-185516

2. Bordin IA, Duarte CS, Ribeiro WS, Paula CS, Coutinho ES, Sourander A, et al. Violence and child mental health in Brazil: The Itaboraí Youth Study methods and findings. Int J Methods Psychiatr Res. 2018. https://doi.org/10.1002/mpr.1605 [cited 2019 May 30]

3. Rønning JA, Handgaard BH, Sourander A (2004) Selfperceived peer harassment in a community sample of Norwegian school children. Child Abuse \& Neglect, 28(10):1067-1079. doi: 10.1016/j.chiabu.2004.04.006 